\title{
Kitap Eleştirisi: Hubbard, P. (2017). The Battle for the High Street: Retail Gentrification, Class and Disgust. Londra: Palgrave Macmillan.
}

\author{
Meriç Kırmızi ${ }^{1}$ \\ İdealKent Dergisi
}

\section{Öz}

Başlığı Anacadde için Savaş: Perakende Soylulaştırması, Sınıf ve Tiksinti diye çevrilebilecek olan Hubbard'in (2017) kitabi Ingiltere'de "High Street" diye bilinen, merkezi alışveriş caddelerinde yaşanan ticari soylulaştırma konusu ile ilgilidir. Hubbard (2017) bu kitabıyla İngiltere kentlerinin anacaddelerinde süre giden değişimin yoğun bir tanımlamasını yapıyor ve kapsamlı bir çözümlemesini sunuyor. Ayrıca, değişen ya da soylulaşan İngiliz anacaddelerindeki toplumsal ayrllklarl, sorunu çevreleyen egemen söylemleri ve bu söylemlerin sorunsallaştırdı ğı ticari işletmeleri inceleyerek araştırıyor. Yazara göre, anacaddelerdeki işçi sinıfinın toplumsal mekânlarım karşısına alan soylulaştırıcı söylem, yalnızca gizli ahlaki duygular barındırmakla kalmaz, aynı zamanda toplumsal temizliğe, sosyal güvenliğe, kamu să̆lığına ve çevre korumaya ilişkin açık ya da kapalı göndermelerde bulunur. Kitabın anacaddelerin yeniden canlandırılmasının buraları, işçi sınıfı kullanımı pahasına orta ve üst sını tüketim mekânları yaptığı yolundaki savı farklı İngiliz kentlerinden birincil ve ikincil kaynaklara dayah örneklerle güçlendiriliyor. Bu kitap, genel olarak, soylulaştırma, özel olarak da gelişmiş ülke örneğinde ticari soylulaştırma konusu ile ilgilenen ve bu konuyu bir kez daha sinıfsal, ama yenilikçi bir biçimde, ahlaki boyutuyla da incelemek isteyen tüm sosyal bilim araştırmacıları için önemli bir başvuru kaynă̆ıdır.

Anahtar Kelimeler: Perakende soylulaştırması, anacadde, toplumsal sınıf, tüketim ve ahlak, Ingiliz kentleri

\footnotetext{
${ }^{1}$ Dr. Öğretim Üyesi, Ondokuz Mayıs Üniversitesi, Fen-Edebiyat Fakültesi, Sosyoloji Bölümü, merickirmizi@gmail.com, 03623121919 (1971)

idlealkent@ Kent Araştırmaları Dergisi (Journal of Urban Studies) http://idealkentdergisi.com 
Kitap Eleştirisi: Hubbard, P. (2017). The Battle for the High Street: Retail Gentrification, Class and Disgust. Londra: Palgrave Macmillan. ${ }^{2}$

Başlığı Anacadde için Savaş: Perakende Soylulaştırması, Sinıf ve Tiksinti diye çevrilebilecek olan Hubbard'ın (2017) kitabı İngiltere'de "High Street" diye bilinen, merkezi alışveriş caddelerinde yaşanan ticari soylulaştırma ile ilgili. Yazar İngiltere kentlerinin anacaddelerinde süre giden değişimin yoğun bir tanımlamasını yapıyor ve kapsamlı bir çözümlemesini sunuyor. Aktarılan toplumsal uzlaşmaya dayalı, düzgün ya da sorunsuz bir değişim değil; toplumsal sınıflar arasında bölünmelere yol açan ayırıcı bir süreç. Hubbard değişen ya da soylulaşan İngiliz anacaddelerindeki toplumsal ayrılıkları, sorunu çevreleyen egemen söylemleri ve bu söylemlerin sorunsallaştırdığı ticari işletmeleri inceleyerek araştırıyor. Egemen söylemlere bir örnek, ölmekte olan anacaddeleri canlandırma söylemidir. $\mathrm{Bu}$ tür söylemlerin kent merkezlerindeki çöküntünün günah keçisi yaptığı işletmeler genelde, seks ve kumar gibi yetişkin eğlencelerine yönelik dükkânlar ve hılı yiyecek (fast food) lokantalarıdır. Kitap, kentsel bozulmanın (urban decay) tanımının toplumsal sınıfa ilişkin saklı anlamlar içerebileceğini anlamayı sağlıyor. Bu bakımdan, Bourdieu'nün (1979) Ayrım'ının çağdaş bir türlemesi (versiyonu) gibidir.

Hubbard (2017) anacaddelerin yeniden canlandırılmasının buraları, işçi sınıfı kullanımı pahasına orta ve üst sınıf tüketim mekânları yaptığı yolundaki savını farklı İngiliz kentlerinden birincil ve ikincil kaynaklara dayalı örneklerle güçlendiriyor. $\mathrm{Bu}$ nedenle, bu kitap yalnızca dükkânların yerelden küresele ya da daha doğrusu, özgün (otantik) ya da organik olan, adil-ticaret ve yavaş tüketim mekânlarına dönüşmesinin sakız gibi çiğnenmiş bir anlatısı değil; yenilenmiş tüketim alışkanlıkları üzerinden sınıf kimliklerine edimsel bir varlık kazandıran ahlaklaştırma süreçleri (Hubbard, 2017, s. 9) ile de yakından ilgili. Ne de olsa, günümüz tüketim toplumunda kim

\footnotetext{
${ }^{2}$ Not: Bu kitap eleştirisi, yazarın kendi bloğunda İngilizce olarak daha önce yayınlanmıştır. Yazarın eklemeler içeren Türkçe çevirisi ilk kez İdealKent'te yayınlanmaktadır.
} 
olduğunuz, ne tükettiğinize bağlıdır. Hubbard'ın çalışmasının Bourdieu'nün başyapıtından ayrıldığı nokta ise şurasıdır: Yirminci yüzyılda anamalcı kentsoylu kendisini daha alt sosyo-ekonomik gruplardan zevkleri ve yaşam tarzının genelindeki güzelduyu (estetik) anlayışı ile ayrıştırırken, kapitalizmin neoliberal aşamasında belli ki artık ötekilerin görüntüsüne ya da varlığına bile katlanamıyor. Hubbard'ın deyişiyle, “orta sınıflar 'neoliberal' kent politikasının yardımıyla kent merkezini geri alıyor ve işçi sınıfı parçalanıyor" (a.g.e., s. 8). Kisacas1, postmodernizm altında kapitalizm, ilkel, saldırgan özüne geri döndü ve kent yurttaşları bu havayı soluyor.

Giriş bölümünden sonra, Hubbard (2017) tasarruf (austerity) İngiltere'sinin ölmekte olan anacaddeyi yenileme retoriğinin çevresinde dönen perakende politikasını çözümlüyor. Bunun için, toplumun daha yoksul üyelerini hedefleyen belirli işletmelerin, ki bunun içinde bahis bayileri, bağış dükkânları, gece kulüpleri ya da pound ve 99 sent (bizdeki 1 milyoncular gibi) zincir mağazaları vardır, anacaddenin sözde ölümünün günah keçileri yapıldığının altını çiziyor. Yazarın savunduğu daha kapsayıcı bir anacaddenin karşısında, "içerisinde belli üst sınıf işletmelerin kabul görüp, genellikle daha az varlıklıların ayağının alıştığı diğerlerinin ise sağlıksı, istenmeyen ve hatta zehirleyici olarak görüldüğü (MKsözde) 'herkes için' bir anacadde kurgusu"(a.g.e., s. 25) yer alır. Üçüncü bölümde yazar kent merkezinin anacaddesindeki perakende soylulaştırmasını, tüketmedikleri için istenmeyenleri dışarıda tutmak üzere tasarlanmış modern agoralar (ya da ters hapishaneler) olarak kent dışındaki alışveriş merkezleriyle karşılaştırarak, perakende sermayesinin bunun kentteki benzerini yaratmaya yönelik bir girişimi diye yorumluyor. Dördüncü bölümde, Hubbard bir zamanlar İngiltere'nin en kötü anacaddelerinden biri kabul edilen Margate'i (İngiltere'nin Güneydoğu sahilindeki bir tatil kasabası), başarısız anacaddeleri neredeyse tiksinilecek caddeler olarak gösterip, onlara karşı bir tür nefret söylemi geliştiren perakende soylulaştırmasının ahlaki gündeminin merceğinden ele alıyor.

Kitabın izleyen, beşinci, altıncı, yedinci ve sekizinci bölümlerinde anacaddelerdeki gece işletmelerine, seks ticareti yapan dükkânlara, bahisçilere ve paket servisi yapan hızlı yiyecek dükkânlarına karşı ortaya koyulan kamu politikası söylemlerinde ve düzenlemelerinde 
saklı olan tüketim, zevk ve ahlak arasındaki derin sınıfsal bağlantılar yapı sökümüne uğratılıp, açığa çıkarılır. Bunun gibi anacaddelerdeki işçi sınıfının toplumsal mekânlarını karşısına alan soylulaştırıcı söylem, yalnızca gizli ahlaki duygular barındırmakla kalmaz, aynı zamanda toplumsal temizliğe, sosyal güvenliğe, kamu sağlığına ve çevre korumaya ilişkin açık ya da kapalı göndermelerde bulunur. İngiltere'nin kamu politikasına göre, eğer lezzetli ya da ucuz olduğu için hızlı yiyecek tüketmeyi yeğliyorsanız, hem kendinize zarar veriyor ve obez olma riski taşıyorsunuz, hem de yerli ve sorumlu bir biçimde tüketmeyerek, iklim değişimi sorununu ağırlaştırıyorsunuz. Basitçe söylemek gerekirse, ekosistemi korumak m1 istiyorsunuz, o zaman adil ticaret uygulamalarıyla yetiştirilmiş kahve çekirdeklerinden yapılma ve iki kat daha pahalı kapuçino için! İngiliz anacaddelerine ilişkin bunun gibi neoliberal sorumlulaştırma söylemi altına gizlenmiş sterilize edici uygulamalar, kentte işçi sınıfının varlığı için çok az alan bırakır, çünkü bu insanlara gerçekte sorumlu bir özne olmanın sosyo-ekonomik araçları sağlanmaz. Bunun yanında, anacaddeden ucuz mağazaların çıkarılması, aynı zamanda yoksulların kendileri gibi olan kişilerle çok para harcamadan buluşup, zaman geçirebilecekleri toplumsallaşma mekânlarının ellerinden alınması demektir (Hubbard, 2017, s. 193).

Sondan bir önceki bölümde Hubbard (2017) kentteki ve yine Margate örneği üzerinden, deniz kıyısındaki kültür öncülügüunde kentsel yenilemeyi (culture-led urban regeneration) inceleyerek, soylulaştırmanın kültürel boyutunu ele alıyor. Bu bölüme son günlerin yaygın kavramlarından olan dirençlilik ve Richard Florida'ya göndermeyle, yaratıcılık çevresindeki tartışmaları da katıyor. $\mathrm{Bu}$ kitapla eş zamanlı olarak okuduğum Florida'nın (2018) Yeni Kentsel Kriz: Soylulaştırma, Eşitsizlik ve Seçkinler Şehri ile Gelen başlıklı kitabı, Hubbard'ınkinden farklı olarak kentsel yenilemenin karanlık yüzü ile ilgili gönülsüz ve geç kalmış bir açıklama izlenimi veriyor. Hubbard'ın kitabının kültürle ilgili olan bu dokuzuncu bölümünde uymacı (konformist) olmadığı varsayılan sanatçıların neoliberalizmin temsilcileri olmalarındaki çelişki vurgulanır; oysa, geçmişte ve bugün kapitalist siyasetlerin parçası konumundaki sanatçıların varlığı bilinir (Aguilera, 2018, s. 136). Sanatçılarınkine benzer, ama tersinden bir çelişki ise, kurumsal hızlı yiyecek dükkânlarının yoksulların sığınağı olmasında görülür. Kültür öncülügünndeki kentsel yenileme ilgili 
olarak yazar, "yaratıcı politikalar anacaddenin çekiciliğini genişletmede başarılı olabilirler mi, yoksa yalnızca perakende mekânlarının 'butikleştirilmesi'ni ve soylulaştırılmasını mı hızlandırırlar" (Hubbard, 2017, s. 201) sorusundan anlaşılacağı gibi, eleştirel bir tavır sergiliyor. Ona göre, şu anda işlerin yolunda gittiği Margate için de henüz karar vermek için erkendir, çünkü Leslie Kern'in deyişiyle, "soylulaştırmanın 'yavaş şiddeti"'nin (a.g.e., s. 212) etkileri geç açığa çıkar. Margate örneği, İngiltere'nin sahil kentlerinin de perakende soylulaştırmasına dayalı kent ekonomisinin ve etiğinin dışında kalmadığını göstermesi bakımından, Türkiye'nin batı kıyılarından kimi örnekleri andırır.

Hubbard, sonuç bölümünde Henri Lefebvre, Rob Shields, Tom Slater, Loic Wacquant, Sarah Schulman ve diğerlerinden de destek alarak, anacaddelerin "son ölüm" aşamasında olmadığı ve kentin, özellikle işçi sınıfından yaşayanlar için önemli sosyo-kültürel roller oynamayı sürdürdüğü yönündeki savını yeniden dile getiriyor (Hubbard, 2017, s. 230). Öte yandan, yenilemeye bütünüyle karşı olmadığının ya da boş dükkânların olduğu gibi kalmasını önermediğinin de altını çiziyor. Bununla birlikte, İngiliz anacaddesi için ortaya koyduğu gelecek öngörüsü, yoksulları ve varlıklıları bir arada kapsayacak biçimde, gerçek anlamda bütün insanlar için düzenlenecek bir mekândır. Yani, yalnızca "kent yaşantısı için bir prim ödemeye hazır olup, anacaddenin kendi soylulaştırılmış yaşam tarzlarına uymasını bekleyen, havalı, genç ve varlıklı kitleler" (a.g.e., s. 200) için olan bir yer değil.

Hubbard'ın kitabı soylulaştırma araştırmasını sınıf dinamiklerini öne çıkararak, yeniden ayakları üzerine dikiyor. Aynı zamanda, kitabın resme ahlak boyutunu katmış olması, uluslararası soylulaştırma yazını için değerli bir katkıdır. Açıkça belirtilmiş savlara dayalı, tutarlı bir düşünce çizgisini kitabın bütün bölümlerinde izlemek olanaklıdır. Ancak, yazarın anacaddelerdeki paket servisi yapan hızlı yiyecek dükkânları gibi zincir mağazalarının yoksulların yeme-içme ve sosyalleşme mekânları olarak korunması gerektiği savı pek inandırıcı değildir. Her ne kadar bu yerlerin birçok bağımsız kahve ve lokantadan daha ucuz fiyatları olabilse de, yoksulluğu kurumsal sermaye ile destekleme mantığını benimsemek güçtür, çünkü o zaman bunun dirençlilik kavramının reformcu yaklaşımından bir farkı kalmaz. Buna karşılık, Hubbard'ın İngiltere'deki ahlakçı perakende 
soylulaştırması çalışması, pembe otobüs, pembe AVM, mescitli kebap lokantaları gibi güncel örneklerle, Türkiye'deki "turistik tutuculaşma" ya da "tutucu zenginleşme (soylulaştırma)" diye tanımlanabilecek sosyo-mekânsal eğilimleri anlamak için bir ölçüt oluşturabilir.

Sonuç olarak, Anacadde için Savaş: Perakende Soylulaştırması, Sınıf ve Tiksinti kitabı genel olarak, soylulaştırma, özel olarak da gelişmiş ülke örneğinde ticari soylulaştırma konusu ile ilgilenen ve bu konuyu bir kez daha sınıfsal, ama yenilikçi bir biçimde, ahlaki boyutuyla da incelemek isteyen tüm sosyal bilim araştırmacıları için önemli bir başvuru kaynağıdır. Ayrıca dikkate değer, çağdaş bir sosyolojik çalışma niteliğindedir.

\section{Kaynaklar}

Aguilera, T. (2018). The Squatting Movement(s) in Paris: Internal Divides and Conditions for Survival. M. A. Martínez López (Der.), The Urban Politics of Squatters' Movements içinde (ss. 121-144). New York, NY: Palgrave Macmillan.

Bourdieu, P. (1984). Distinction : A Social Critique of the Judgement of Taste. (R. Nice, Çev.). Cambridge, Massachussets: Harvard University Press. (Orijinal eserin yayın tarihi 1979).

Florida, R. (2018). Yeni Kentsel Kriz: Soylulaştırma, Eşitsizlik ve Seçkinler Şehri ile Gelen. (D. N. Özer, Çev.). İstanbul: Doğan Kitap. (Orijinal eserin yayın tarihi 2017).

Hubbard, P. (2017). The Battle for the High Street: Retail Gentrification, Class and Disgust. Londra: Palgrave Macmillan. 